\title{
Difficulties of Integrating Human Resources Management Globally by
}

\section{Japanese Corporations}

\author{
Kentaro Takakuwa \\ Guest Researcher, Institute of Policy and Cultural Studies of Chuo University \\ Tokyo, Japan \\ Kentaro.takakuwa@gmail.com
}

(Received August 2, 2021 Revised August 26, 2021 Accepted September 15, 2021, Available online December 1, 2021)

\begin{abstract}
International enterprises should integrate human resource management globally under a multi-dimensional global market. But the globalized level of Japanese companies' human resource management has been low for decades. This might have structural causes, then they couldn't execute necessary policy change. I found this structural problem which prevents Japanese companies from offering attractive job opportunities to foreign workers through international comparison of the relation between labor market and incentive system to attitudes of work. The experienced labor market is imperfect only in Japan. This situation enhances the accumulation of "context-oriented human assets". Seniority based rewards systems promote them to co-operate then increase the performance of this kind of human asset. In contrast, "independent human asset" would be accumulated in other countries, such as South Korea, China, Indonesia, United States and Brazil, except Germany. The experienced labor market is relatively perfect in these countries, and those who put priority on both good rewards and clear career path when seeking job opportunities get good rewards. Because this kind of incentive system seen in the countries except Japan and Germany have inconsistency with that is seen in Japanese homeland office, Japanese companies couldn't integrate human resource management globally. Japanese companies need a fundamental change of organizational architecture to regain the international competitiveness and utilize the new market opportunity overseas.
\end{abstract}

Keywords: J-System, H-System, Labor Market, Individual Human Asset, Context-Oriented Human Asset, Incentive System.

\section{Introduction}

With the global integration of the market, regional differentiation, and structure changes of industries caused by technological innovation, the international market structure has been diversified. Doz, Santos \& Williamson [1] states the necessity of existing multinational companies to evolve into a "transnational enterprise" under this environment. And Bartlett \& Ghoshals [2][3] claimed also the necessity of them to reborn as a "meta-national enterprise". Oviatt \& McDougall [4] has proposed a company model called as "Born Global Companies", which is built on the premise of global business development from its inception, for start-up in the same context. The essential of these models is that companies should have several skills simultaneously to build competitive advantages under the environment of multidimensional changes occurring. The skills include the flexibility of the multinational type, the efficiency seen in the global type, and the ability to transfer overseas innovation, which is good at the international type.

Meanwhile, Furusawa [5] mentioned that the strategic goal of global human resource management is just achieve the globalization of Japanese employees, and its international resource management is an ad hoc "low integrated - low Local adaptation" type. For Japanese companies, "localization delay" is frequently pointed out as a problem of international human resource management (Bartlett \& Yoshihara [6]). For example, in the early the 1990s, Koop [7] pointed out that the level of the globalization of the human resource system of Japan enterprise is remarkably low compared with western companies from four aspects, global integration level of performance evaluation system, education and training scheme to appoint local staff as headquarter staff, international personnel exchanges between local offices, existence of global information system of human resources. This situation is still existing today. Ghemawat and Vantrappen [8] compares the ratio of foreign officers in the Fortune Global 500 Company in 2014 internationally, which indicating that the personnel globalization of Japanese companies is not progressed. According to Iwasaki [9], Japanese-style human resources management prevent the Japanese international companies from 
integrating of human resource management system, such as teamwork by generally job assigned workers, or slow promotion speed of seniority-based incentive system.

While the global integration of international human asset management of Japanese companies has not advanced, the declining international competitiveness of Japanese companies has been pointed out since the late 1990s. For example, in the ICT industry or the high-tech sector, the decline in the sales share of Japanese companies (Ministry of Public Management's "ICT Competitiveness Index in the Heisei 27th Edition"), declining Japan's added value share (National Science Foundation "Science and Engineering Indicators 2016"), Then, it can be confirmed that the Japanese company's R\&D investment efficiency decline (Otsuka [10]). To restore the competitiveness of Japanese companies, they need to gain access to market opportunities in overseas markets, e.g. conversion led by government from gasoline cars to electric cars in Europe. Furthermore, because we face the weekend vitality of the human resources in Japanese headquarters caused by the declining population of youth, and it became the urgent strategic matters to revive the organization by utilizing of overseas human resources, and globalizing human resource management system.

However, why Japanese firms cannot overcome the its side effect of personnel system already pointed out twenty years ago, and will not be able to proceed "global integration" of international human resource management. In this paper, we explore the answer to this research question by the following procedure. First, in Section 2 we derive the hypotheses about the factors, which keep Japanese international companies away from integrating global human resources management, from the literature review of theoretical enterprise architecture model and its complementary relationship with external resource markets. In chapters 3 and 4, I analyzed international survey about the view of career of university graduate citizens from $20 \mathrm{~s}$ to 30 s, and verified the hypothesis. Finally, in Chapter 5, based on the discussions in chapters 3 and 4, I will discuss how we could develop the way to global integration of international human resources management for Japanese international companies.

\section{Complimentaries Between The Element of J Systems}

Certain management systems co-evolve with social accumulation of specific human asset types. It is thought that this social accumulation inhibits the change of personnel system. Therefore, I'll overview the work of Aoki, which approached the cause of corporate behaviors' differences between countries from the view of new institutional school, and confirmed what kind of human assets, labor market, incentive system the management systems became the bases of such as the Japanese management system, the US management system and the Germany management system etc. Then, I present a hypothesis on what could be a factor hindering the integration of global human asset management by Japanese companies.

\subsection{Elements of the Japanese management system and their complementary relationship}

Aoki [11] [12] modeled the characteristics of Japanese companies as a six-element integrated system (J system). "Horizontal information system (I)" represented by team work operations by generally job assigned worker, "rank hierarchy (R)" represented by seniority-based wage system and late promotion, "Incomplete labor market (E)" represented by the remarkably small experienced labor market comparing with new graduate labor market, "subcontracting relationship (S)" which subcontracts different activities from the perspective of internal activities and is externalized using a company or spun off subsidiary, "Main bank relationship (MB)" that relies on banks, and "cross-shareholding" that contributes to the establishment of a stable relationship with shareholders constitute a Japanese management system.

Complementary relationship exists among these elements. For example, enterprises commit to total wage payments to workers by long-term employment and seniority-based wage and promotion system increase incentives for workers investing in company-specific human capital (Kanemonto and Mcleod [13]; Carmichael [14]). On the other hand, since Japanese companies adopt horizontal information processing in which the scopes of each members' authority and responsibility are unclear, externalities of performance exist between individual duties. In such a case, it is known that using performance-based evaluation as a promotion criterion induces sabotage that interferes with the work of other workers and causes dysfunction of team work (Lazear [15]). 
In this sense, "incomplete labor market" and "seniority-based wage and promotion system" are complementary to "horizontal information system", and "context-oriented human assets". Aoki [16] stated this complementarity cause the social accumulation of "context-oriented human asset" proceed. Horizontal information processing has advantages only in industries with moderate market and technology uncertainties, but the social accumulation of "context-oriented human asset" force the almost company adopt J-systems even in the industries which would not fit the J-system.

\subsection{Complementary relationship between diverse management systems and labor market}

Then, what other management systems have developed through certain accumulation of labor market and human assets? The five generic modes of organizational architecture (Table 1) are presented by Aoki [17]. These models include the $\mathrm{S}$ mode which is the traditional J-system already mentioned, the $\mathrm{H}$ mode which is the traditional US enterprise system, the G mode which is found in the German company, the SV mode which is found in the industry cluster of Silicon Valley, and RE mode found in manufactures led by heavy weighted project leaders and knowledge intensive professional organizations. These models are segregated by the level of essentiality of both utilize management's cognitive assets (=MCA) and workers' cognitive resources (=WCA) to expand the marginal product by utilizing nonhuman physical assets (=PHA). I'll summarize that in what kind of both labor and goods market three modes, such as $\mathrm{H}$ and $\mathrm{S}$ and $\mathrm{G}$, work efficiently or effectively.

Table. 1. Five Fundamental Organizational Architectures

\begin{tabular}{|llll|}
\hline & $\mid$ WCA & & \\
& $\mid$ Essential & $\mid$ Quasi-essential & $\mid$ Non-essential \\
$\mid$ Essential & $\mid$ RE $:($ H-S/E) & $\mid$ H: (H-E) & $\mid$ H: (H-E) \\
& $\mid$ MCA & & \\
| Quasi-essential & $\mid$ SV: (S-E) & $\mid$ G: (S-E/S), S: (S-S) & $\mid$ \\
\hline
\end{tabular}

The expansion of marginal products in the $\mathrm{H}$ mode mainly depends on MCA specialized decision making and the WCA is only responsible for functionally subdivided limited decision making. WCA can easily exchange MCA through almost complete labor market. This management system has a comparative advantage in the standard product markets where PHA is very simple or very complicated, and the introduction stage of new markets in which the prompt decision by management is essential.

Expansion of marginal products in S type management system requires cooperation of MCA - WCA and WCA WCA to perform vertical and horizontal information processing. The lower the value of the external labor market, the better the incentive to commit to this partnership, the better the function in the economic sphere with the incomplete labor market. This management system has a comparative advantage in reacting to the market with diversified product specification by continuously tweaking the coordination method at the field level [11] [18] [19].

Expansion of marginal products in the G-type management system is achieved by WCA and MCA highly trained and organized at the industrial level, in cooperation with each other vertically and horizontally to make decisions. Individual WCAs are interchangeable within the industry, but this cooperative relationship is institutionally obliged and functioning in Germany. Companies under this management system can enjoy a high product quality reputation because of national and industrial vocational training programs, tradition of labor ethics based on craftsmanship technology.

\subsection{Hypothesis of factors hindering globalization of human resources management}

From the discussion so far, difference of effective incentive system in between Japan and others, caused by the accumulated human assets type, accompanied with certain type of labor market, is the reason why Japanese companies couldn't reach the global integration of international human management. In other words, the following 
three hypotheses can be presented as factors that prevent Japanese companies from integrating human resources management permanently.

Hypothesis 1: Japanese labor market is especially incomplete so that suppresses the ones will to change job

Hypothesis 2: Different human assets are accumulated against the background of differences in labor market

Hypothesis 3: a. Each company adopts an incentive system suitable for certain accumulated human assets, b. As a result, the social incentive system lose flexibility

Figure 1 shows the structures of these hypnoses. The conflict between both fixed incentive system in Japan and in foreign branches caused the delay of global integration of human resources management.

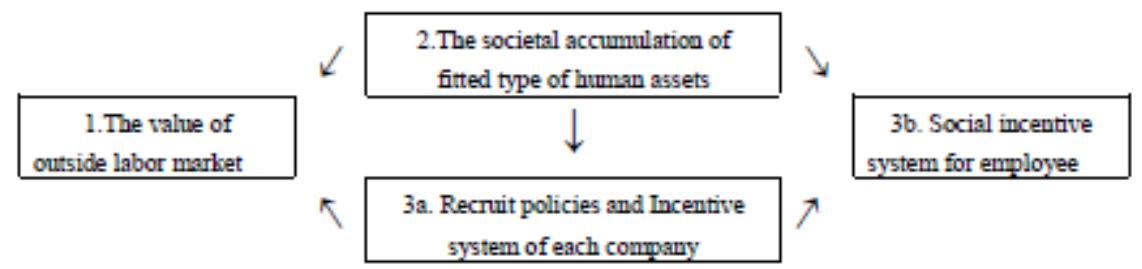

Figure. 1. The structure of hypothesis

\section{Country Differences of External Labor Market Value}

I will verify the hypothesis presented in Chapter 2 through international comparative analysis of the attitudes about career in Chapters 3 and 4. Firstly I overviewed the survey, and after I confirmed the specialty of Japanese labor market and evaluation system, by international comparison of the result of job change experience to employment status, and salary level etc. In the next chapter, we confirm the mismatch between the Japanese employment system and the motivations of overseas local talent, through the international comparison of the relationship between work motivation and career change experience, job motivation and relationship of salary change after career change.

\subsection{Research outline of "Working Person 2012 Survey"}

In the analysis of this thesis, we received the individual vote data of "Global Career Survey, 2012 (Recruit Works Institute) " from the SSJ data archive of the social survey and data archive research center attached to the Institute of Social Science of The University of Tokyo. This data consists of 13 countries which integrated a part of data of "Working Person Survey, 2012" (SSJDA 0870) as a Japanese survey into the data of the 12 countries of the Global Career Survey. I picked up 7 countries, such as Japan (JP), South Korea (KR), China (CH) America (US), Germany (DE), Brazil (BR) from the survey.

The data are allocated equally to 150 for each gender and 10-year age group (excluding college graduates) aged 20 to 39 university graduates who are currently working. It was collected through Internet surveys conducted from September to December 2012.

To overview the characteristics of the labor market in each country, we compare the employment pattern (Table 2), contract type (Table 3), work position (Table 4), job change experience (Table 5) based on the results of t-test. Looking at the form of employment, it can be confirmed that part-time employees in Japan, Germany, the United States and Brazil are larger than other countries. Looking at the contract form, it can be confirmed that in Japan, China and Germany there are more temporary contracts than other countries. Looking at the position of work, the ratio of managers in China is high, low in Japan and South Korea, not great difference in average level in other countries. Finally, when looking at job change experience, it is confirmed that the rate of job change is high in China and India, low in South Korea, Germany and Brazil, and the average level of Japan and the United States.

Comparing each country data at grand total level, we can confirm the late promotion which is characteristic of the seniority system in Japan, but we couldn't confirm the stable employment contract which is characterized by lifetime employment. In the face of the declining international competitiveness, it is thought that Japanese companies have 
been adopting performance-based measures (from the Social Productivity Headquarters "The 15th Survey on Changes in Japanese Employment and Human Resources"), the abandonment of long-term employment (Ministry of Internal Affairs and Communications "Labor Force Survey Each Year Edition").

Table. 2. Comparison of employment status: Length of work by country

Employment Status: Length of work

\begin{tabular}{|c|c|c|c|c|c|c|c|c|}
\hline Unit: $\%$ for base & TOTAL & JP & $\mathrm{KR}$ & $\mathrm{CH}$ & $\mathrm{ID}$ & $\mathrm{DE}$ & US & BR \\
\hline BASE & 3876 & 601 & 580 & 602 & 502 & 555 & 536 & 500 \\
\hline Full-time $(>=35 \mathrm{~h} / \mathrm{w})$ & 89.6 & $\bar{\nabla} 85.9$ & 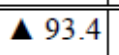 & $\mathbf{\Delta} \boldsymbol{\Delta} 99.7$ & $\bar{\Delta} \boldsymbol{\Delta} 93.4$ & $\bar{\nabla} 85.9$ & $\bar{\nabla} 85.4$ & $\bar{\nabla} 81.8$ \\
\hline Part-time ( $<35 \mathrm{~h} /$ week) & 10.4 & $\Delta 14.1$ & $\boldsymbol{\nabla} 6.6$ & $\boldsymbol{\nabla} 0.3$ & $\boldsymbol{\nabla} 6.6$ & $\Delta 14.1$ & $\Delta 14.6$ & $\boldsymbol{\Delta} 18.2$ \\
\hline
\end{tabular}

* Significat level: " $\boldsymbol{\Delta} \nabla " 1 \%, " \triangle \nabla " 5 \%, " \uparrow \downarrow " 10 \%$

Table. 3. Comparison of employment status: Term of contract by country

Employment Status: Term of contract

\begin{tabular}{|c|c|c|c|c|c|c|c|c|}
\hline Unit: $\%$ for base & TOTAL & JP & $\mathrm{KR}$ & $\mathrm{CH}$ & $\mathrm{D}$ & $\mathrm{DE}$ & US & $\mathrm{BR}$ \\
\hline BASE & 3876 & 601 & 580 & 602 & 502 & 555 & 536 & 500 \\
\hline Permanent & 78.9 & $\boldsymbol{\nabla} 74.5$ & $\overline{\Delta \Delta} 84.0$ & $\boldsymbol{\nabla} 71.1$ & $\uparrow 82.1$ & $\mathbf{\nabla} 68.6$ & $\boldsymbol{\Delta \Delta} 86.4$ & $\bar{\Delta} \mathbf{\Delta} 88.2$ \\
\hline Temporary & 21.1 & $\boldsymbol{\Delta} 25.5$ & $\boldsymbol{\nabla} 16.0$ & $\Delta 28.9$ & $\downarrow 17.9$ & $\boldsymbol{\Delta} 31.4$ & $\boldsymbol{\nabla} 13.6$ & $\boldsymbol{\nabla} 11.8$ \\
\hline
\end{tabular}

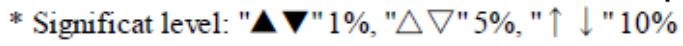

Table. 4. Comparison of current position by country

Current position

Unit: \% for base

\begin{tabular}{l|r|r|r|r|r|r|r|r} 
Unit: \% for base & TOTAL & \multicolumn{1}{c|}{ JP } & \multicolumn{1}{c|}{ KR } & \multicolumn{1}{c|}{ CH } & \multicolumn{1}{c|}{ D } & \multicolumn{1}{c|}{ DE } & \multicolumn{1}{c}{ US } & \multicolumn{1}{c}{ BR } \\
\hline \hline BASE & 4243 & 601 & 613 & 617 & 605 & 606 & 601 & 600 \\
\hline \hline Manager & 27.4 & $\boldsymbol{\nabla} 19.3$ & $\boldsymbol{\nabla} 14.8$ & $\boldsymbol{\Delta} 51.7$ & 26.6 & 26.6 & 26.5 & 26.0 \\
Not a manager & 72.6 & $\boldsymbol{\Delta} 80.7$ & $\boldsymbol{\Delta} 85.2$ & $\boldsymbol{\nabla} 48.3$ & 73.4 & 73.4 & 73.5 & 74.0
\end{tabular}

* Significat level: " $\boldsymbol{\Delta} \boldsymbol{\nabla} " 1 \%, " \triangle \nabla " 5 \%, " \uparrow \downarrow " 10 \%$

Table. 5. Comparison of the rate of job change experiences by country

Experience of Job Change

\begin{tabular}{l|r|r|r|r|r|r|r|r} 
Unit: \% for base & TOTAL & \multicolumn{1}{c|}{ JP } & \multicolumn{1}{c|}{ KR } & \multicolumn{1}{c|}{ CH } & D & \multicolumn{1}{c|}{ DE } & US & \multicolumn{1}{c}{ BR } \\
\hline BASE & 4243 & 601 & 613 & 617 & 605 & 606 & 601 & 600 \\
\hline \hline No & 51.5 & 50.7 & $\Delta 56.1$ & $\mathbf{\nabla} 38.9$ & $\mathbf{\nabla} 39.7$ & $\boldsymbol{\Delta} 66.3$ & 52.6 & $\Delta 56.5$ \\
Yes & 48.5 & 49.3 & $\nabla 43.9$ & $\boldsymbol{\Delta} 61.1$ & $\boldsymbol{\Delta} 60.3$ & $\boldsymbol{\nabla} 33.7$ & 47.4 & $\nabla 43.5$
\end{tabular}

* Significat level: " $\boldsymbol{\Delta} \boldsymbol{\nabla} " 1 \%, " \triangle \nabla " 5 \%, " \uparrow \downarrow " 10 \%$

\subsection{Influence of Job change experience on employment and promotion opportunity and salary}

level

Teamwork (Furusawa [5]), an advantage of Japanese human resource management, is supported by motivation for individuals to invest in the company-oriented skill acquisition (Aoki et al. [20]). This kind of motivation is promoted under the low value of external labor market environment. Then is the value of external labor market low in DE, or high in US? I'll confirm the hypnoses by the result of t-test about the correlation between job change experience and promotion speed, job change experience and income level, job change experience and employment state (time / period).

Table 6 and Table 7 show the influences of job change experiences to contract aspects of both working hours and contract term, by country. First, looking at Table 6, in Japan the proportion of part-time workers is high among in job changers, and the proportion of full-time workers are high in South Korea and Indonesia. Then, looking at Table 7, we see that in Japan, the percentage of contracts with temporary contracts is higher, in China, Indonesia, Germany, and the United States the proportion of permanent contracted workers is higher.

Table 8 summarizes whether the percentage of managerial positions is affected by the experience of job change. According to this, in Japan, Germany, Brazil, the percentage of managers does not change with or without job change experience, and in South Korea, China, Indonesia, US you can see that the percentage of managers are more in job change experienced person. 
Table 9 summarizes the relationship between job change experience and salary. Looking at this, in Japan it can be confirmed that many people with job change are under 3 million yen in annual income.

Table. 6. The influences of job-change experiences on the contract of length of work time

Length of work by job-change experiences (Full time work $>=35$ hours/week, Part time work $<35$ hours/week)

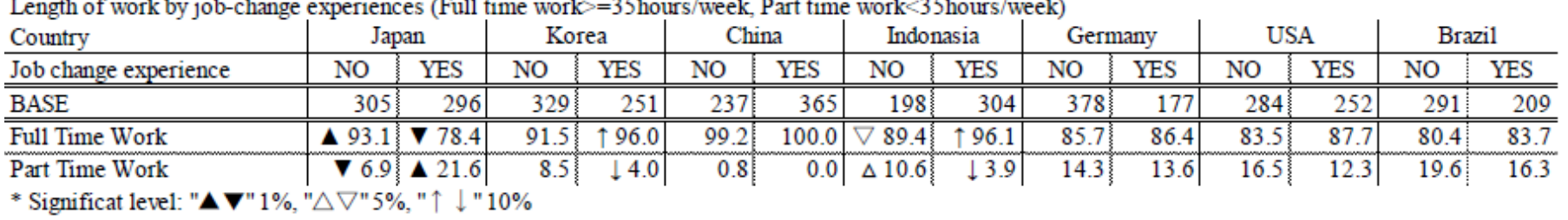

Table. 7. The influences of job-change experiences on the term of employee contract

Term of contract by job-change experiences

\begin{tabular}{|c|c|c|c|c|c|c|c|c|c|c|c|c|c|c|}
\hline Country & $\mathrm{Jat}$ & & Ko & & Chi & & Indo & nasia & Gern & lany & US & & $\mathrm{Br}$ & \\
\hline Job change experience & NO & YES & NO & YES & NO & YES & NO & YES & NO & YES & NO & YES & NO & YES \\
\hline BASE & 305 & 296 & 329 & 251 & 237 & 365 & 198 & 304 & 378 & 177 & 284 & 252 & 291 & 209 \\
\hline Permanent & $\Delta 85.6$ & $\bar{\nabla} \mathbf{\nabla} 63.2$ & 83.0 & 85.3 & $\nabla 64.1$ & 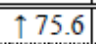 & $\nabla 75.3$ & $\Delta 86.5$ & 65.6 & 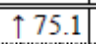 & $\downarrow$ & (†90.5 & 88.3 & 88.0 \\
\hline Temporary & $\boldsymbol{\nabla} 14.4$ & $\boldsymbol{\Delta} 36.8$ & 17.0 & 14.7 & $\Delta 35.9$ & $\downarrow 24.4$ & $\Delta 24.7$ & $\nabla 13.5$ & 34.4 & $\downarrow 24.9$ & $\uparrow 17.3$ & $\downarrow 9.5$ & 11.7 & 12.0 \\
\hline
\end{tabular}

Table. 8. The influences of job-change experiences on organizational position

Current position by job cange experience

\begin{tabular}{|c|c|c|c|c|c|c|c|c|c|c|c|c|c|c|}
\hline Country & $\mathrm{JH}$ & & $\mathrm{K}$ & & $\mathrm{C}$ & & I & & $\mathrm{D}$ & & $\mathrm{U}$ & & B & \\
\hline Job change experience & NO & YES & NO & YES & NO & YES & NO & YES & NO & YES & NO & YES & NO & YES \\
\hline BASE & 305 & 296 & 344 & 269 & 240 & 377 & 240 & 365 & 402 & 204 & 316 & 285 & 339 & 261 \\
\hline Manager & 18.0 & 20.6 & $\boldsymbol{\nabla} 9.6$ & $\Delta 21.6$ & $\nabla 44.2$ & $\uparrow 56.5$ & $\boldsymbol{\nabla} 18.3$ & $\Delta 32.1$ & 25.4 & 28.9 & $\nabla 20.9$ & $\Delta 32.6$ & 24.5 & 28.0 \\
\hline Not a manager & 82.0 & 79.4 & $\boldsymbol{\Delta} 90.4$ & $\boldsymbol{\nabla} 78.4$ & $\Delta 55.8$ & $\downarrow 43.5$ & $\boldsymbol{\Delta} 81.7$ & $\nabla 67.9$ & 74.6 & 71.1 & $\Delta 79.1$ & $\nabla 67.4$ & 75.5 & 72.0 \\
\hline
\end{tabular}

Table. 9. Annual income level by job-change experiences

Annual income level by job-change experience

\begin{tabular}{|c|c|c|c|c|c|c|c|c|c|c|c|c|c|c|}
\hline Country & Ja1 & & Ko: & & $\mathrm{Ch}$ & & Indor & asia & Germ & lany & US & & $\mathrm{Bra}$ & \\
\hline Job change experience & NO & YES & $\mathrm{NO}$ & YES & NO & YES & NO & YES & NO & YES & NO & YES & NO & YES \\
\hline BASE & 298 & 284 & 316 & 256 & 238 & 376 & 231 & 349 & 365 & 194 & 297\{ & 263 & 308 & 242 \\
\hline Less than 1 million JPY & $\downarrow \downarrow 4.4$ & $\uparrow \uparrow 9.9$ & $\uparrow 34.8$ & $\nabla 24.2$ & 43.3 & (35.4 & 88.3 & 83.7 & $19.5\}$ & $\nabla 10.8$ & 11.1 & 9.5 & 54.5 & "54.1 \\
\hline Less than 3 million JPY & $\downarrow 20.5$ & $\uparrow 29.6$ & 52.2 & 58.2 & 51.7 & 51.1 & 9.5 & 13.8 & 20.0 & 19.6 & 21.2 & 19.4 & 31.5 & 33.1 \\
\hline Less than 5 million JPY & $\Delta 48.7$ & $\boldsymbol{\nabla} 33.8$ & 17.9 & $\uparrow 14.5$ & +3.8 & 8.5 & 1.3 & 2.0 & 35.6 & 38.71 & 30.0 & 32.3 & 6.2 & 7.4 \\
\hline Less than 7 million JPY & 18.5 & 19.0 & 4.1 & 1.6 & $\downarrow 0.4$ & 3.5 & 0.0 & 0.6 & 18.1 & 20.1 & 17.5 & 17.9 & 4.2 & 2.5 \\
\hline 7 million JPY or Over & 8.1 & 7.7 & 0.9 & 1.6 & 0.8 & 1.6 & 0.9 & 0.0 & 6.8 & 10.8 & 20.2 & 20.9 & 3.6 & 2.9 \\
\hline
\end{tabular}

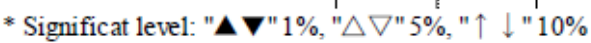

\subsection{The uniqueness of Japanese labor market}

Here, I summarized the effect of job change experience on promotion, income, employment form. There are many more unfavorable employment opportunities in the experienced labor market in Japan, and as a result, you can see that the salary level of the job changers is decreasing. Meanwhile, there is a possibility that more advantageous employment opportunities exist in job changer markets in other countries. Firstly, it is confirmed in South Korea, China, Indonesia and the United States that both stable employment contracts and promotion opportunities are offered to experienced labor. In Germany, it is confirmed that the more stable employment opportunities are offered to more experienced workers.

In other words, in the five countries of South Korea, China, Indonesia, the United States and Germany the better opportunities of employment are offered to the experienced worker, except in Japan. The value of other companies' work experience is not evaluated in Japan. 


\section{Social Incentive Structures on Attitude to Work}

Here, I'll investigate what kind of job attitude differences have been seen between countries, based on the labor market value gap between inside and outside of enterprises. And, I'll illustrate what kind of workers are evaluated in each country in regarding the attitude of work.

\subsection{Relationship between the attitude toward the work and the reasons of job change}

First, we present the reasons for changing jobs in Table 10, so that what kind of dissatisfactions drive workers to access the external labor market in each 7 countries. The top three reasons for changing jobs in Japan are job content, employment conditions, and personal relationships in the workplace. Those of South Korea, China and Indonesia Anxiety are dissatisfactions with salary, working conditions, and company's future potential. Meanwhile, those of Germany, the United States and Brazil are anxieties about salary and working conditions, or end of contracts.

Furthermore, the top three common attitudes toward work of each country are emphasized in Table 11. In six countries, other than Japan where the value of the external labor market is relatively high, the importance of rewords such as salary is ranked as top, while in Japan, where the external labor market value is relatively low, the good personal relationship in the workplace is the most important. This difference might indicate the difference of accumulated human asset type. The importance of rewards might be caused by the accumulation of "individual human asset" whose skill is well defined and easily replaced by others. The importance of personal relation in workplace might be caused by the accumulation of "context-oriented human asset" whose marginal production is increase through teamwork.

The second and third priority of job environment in each country would imply the difference of the labor market. For example, the Japanese workers have relatively low negotiation power toward manager because the value of current job opportunity is higher than that of outside job opportunity. Thus, they might put priority on work assignment and appropriate work hours \& holidays. The US workers' competition to get the better job is very intensive, thus they might put priority on work assignment and employment stability. Because Germany workers are essential at industry level but exchangeable at company level, they might put priority on the personal relation in workplace and the employment stability.

Typical J-system enterprise wouldn't offer high salaries, clear job assignments or clear career paths to job changers. Thus, the job opportunity of Japanese company has less attractive than that of foreign company.

Table. 10. The main reason of leaving job by country

\begin{tabular}{|c|c|c|c|c|c|c|c|c|}
\hline & TOTAL & JP & $\mathrm{KR}$ & $\mathrm{CH}$ & $\mathrm{ID}$ & $\mathrm{DE}$ & US & $\mathrm{BR}$ \\
\hline BASE & 2057 & 296 & 269 & 377 & 365 & 204 & 285 & 261 \\
\hline Dissatisfied with salaly & 19.9 & $\boldsymbol{\nabla} 6.8$ & $\bar{\nabla} \nabla 14.5$ & $\Delta 29.7$ & $\Delta 29.0$ & $\underline{\nabla 14.2}$ & 20.7 & $\underline{\underline{\underline{16.9}}}$ \\
\hline Dissatisfied with working conditions, place etc. & 16.0 & $\underline{\underline{16.9}}$ & $\underline{\underline{16.4}}$ & $\underline{14.1}$ & $₫ 19.2$ & $\underline{\underline{16.7}}$ & $\underline{\underline{14.4}}$ & $\underline{14.2}$ \\
\hline Uncertainty about the future of the company etc. & 12.2 & $\overline{10.1}$ & $\underline{13.8}$ & $\widehat{\underline{\Delta 21.5}}$ & $\underline{13.2}$ & $\overline{\mathbf{3} .4}$ & $\boldsymbol{\nabla 7 . 0}$ & 10.3 \\
\hline End of contract & 11.8 & $\boldsymbol{\nabla} 6.1$ & 13.4 & $\boldsymbol{\nabla} 5.0$ & 10.1 & $\Delta 26.0$ & $\underline{12.3}$ & $\triangleq 16.9$ \\
\hline Dissatisfied with nature of work & 9.4 & $\Delta 17.6$ & 11.5 & 11.1 & 7.7 & $\nabla 5.4$ & 8.4 & $\boldsymbol{\nabla} 2.3$ \\
\hline Company went bankrupt & 4.0 & 3.4 & $\Delta 6.7$ & 3.7 & 2.5 & 3.9 & 3.9 & 4.6 \\
\hline To enter to higher level school etc. & 3.9 & $\uparrow 6.1$ & $\uparrow 5.9$ & $\downarrow 2.1$ & $\downarrow 2.2$ & 4.9 & 5.3 & $\downarrow 1.9$ \\
\hline Dissatisfied with personal relations & 3.7 & $\Delta 9.1$ & 2.2 & 3.7 & $\downarrow 1.9$ & 2.9 & 2.8 & 3.1 \\
\hline Marriage, child birth, childcare, nursing & 2.6 & $\Delta 8.4$ & 1.1 & $\nabla 0.8$ & 1.6 & 2.0 & 2.5 & 1.9 \\
\hline Early retirement & 2.4 & 3.4 & 2.2 & 3.4 & $\nabla 0.5$ & 2.0 & 1.8 & 3.8 \\
\hline To work independently & 2.3 & $\nabla 0.3$ & 2.2 & $\nabla 0.8$ & 2.7 & $\Delta 4.4$ & 1.8 & $\boldsymbol{\Delta} 5.4$ \\
\hline Self injury or sickness & 1.2 & $\boldsymbol{\Delta} 5.4$ & 1.5 & $\nabla 0.0$ & 0.3 & 0.5 & 0.4 & 0.4 \\
\hline Other & 10.7 & 6.4 & 8.6 & 4.0 & 9.0 & 13.7 & 18.9 & 18.4 \\
\hline
\end{tabular}

\footnotetext{
* Order of occurrence: No.1=Gray Background, No.2=Double underlined, No. $3=$ Single underlined
} 
Table. 11. Top 3 important elements about job by country

Top 3 important elements of job environment

\begin{tabular}{|c|c|c|c|c|c|c|c|c|}
\hline Unit: $\%$ for base & TOTAL & JP & $\mathrm{KR}$ & $\mathrm{CH}$ & ID & $\mathrm{DE}$ & US & $\mathrm{BR}$ \\
\hline BASE & 4243 & 601 & 613 & 617 & 605 & 606 & 601 & 600 \\
\hline Good rewards (High salaly etc.) & 64.4 & $\boldsymbol{\nabla} 41.4$ & $\Delta 75.0$ & $\Delta 77.0$ & $\Delta 79.8$ & $\boldsymbol{\nabla} 58.7$ & $\nabla 56.1$ & 62.0 \\
\hline Work assignment of you & 41.3 & $\Delta 48.1$ & 41.8 & $\underline{\nabla} 32.6$ & $\lcm{37.9}$ & 40.3 & $\Delta 52.4$ & $\nabla 36.5$ \\
\hline Good personal relation in working place & 40.0 & $\Delta 58.7$ & $\boldsymbol{\nabla} 31.6$ & $\boldsymbol{\nabla} 28.0$ & $\downarrow 36.7$ & $\Delta 55.4$ & $\bar{\nabla} 27.0$ & $\underline{\underline{42.8}}$ \\
\hline Employment stability & 37.4 & 34.8 & $\underline{\Delta} 44.4$ & $\boldsymbol{\nabla} 31.6$ & $\boldsymbol{\nabla} 23.5$ & $\underline{\Delta 42.4}$ & $\Delta 47.6$ & 37.5 \\
\hline Apropriate work hours \& holidays & 33.7 & $\underline{\underline{\Delta} 48.6}$ & $\Delta 50.7$ & $\nabla 30.0$ & $\boldsymbol{\nabla} 24.6$ & $\uparrow 37.3$ & $\boldsymbol{\nabla} 25.1$ & $\boldsymbol{\nabla} 19.5$ \\
\hline Clear career path & 25.1 & $\boldsymbol{\nabla} 9.0$ & $\boldsymbol{\nabla} 11.4$ & $\underline{\underline{\Delta} 51.4}$ & $\Delta 35.4$ & $\boldsymbol{\nabla} 7.4$ & $\boldsymbol{\nabla} 19.8$ & $\underline{\Delta} 41.2$ \\
\hline Place that you want to work & 20.7 & 22.3 & $\nabla 17.5$ & 18.3 & $\boldsymbol{\nabla} 14.5$ & 21.1 & $\boldsymbol{\Delta} 32.3$ & 18.8 \\
\hline Fair evaluation of employee & 14.0 & $\boldsymbol{\Delta} 26.0$ & 13.5 & $\boldsymbol{\nabla} 6.2$ & 12.9 & $\downarrow 11.6$ & 12.1 & 15.8 \\
\hline Opportunity of education etc. & 14.0 & $\boldsymbol{\nabla} 6.0$ & $\boldsymbol{\nabla} 7.0$ & $\nabla 11.2$ & $\boldsymbol{\Delta} 18.7$ & $\boldsymbol{\Delta} 19.1$ & $\uparrow 16.5$ & $\Delta 19.7$ \\
\hline Company's status & 9.4 & $\boldsymbol{\nabla} 5.2$ & $\nabla 7.0$ & $\boldsymbol{\Delta} 13.8$ & $\Delta 16.0$ & $\nabla 6.6$ & 11.1 & $\boldsymbol{\nabla} 6.2$ \\
\hline
\end{tabular}

* Significat level: " $\boldsymbol{\Delta} \boldsymbol{\nabla} " 1 \%, " \triangle \nabla " 5 \%, " \uparrow \downarrow " 10 \%$

* Order of occurrence: No.1=Gray Background, No.2=Double underlined, No.3=Single underlined

\subsection{The type of motivation which would evaluated in each labor market}

Let's consider social incentives systems of each county here. I verified the relation between the workers' attitudes toward job and evaluation of them, through logistic regression analyses by using the statistical analysis software R. Figure 12 shows the variables used for this analysis.

For the first step of analysis, I eliminate the irrelevant variables to evaluation indexes by judging through Fisher's exact test. Then I investigate the correlation between evaluation indicators and attitudes toward work by solving the formula (1). Variable " $\boldsymbol{q}$ " of the formula (1) expresses the achievement rate of each performance indicator, "Xi" represents each score corresponding to each attitude " $\boldsymbol{i}$ ", and " $\boldsymbol{\beta i}$ " represents each coefficient corresponding each attitude " $i$ ". The plus coefficient indicates that the achievement probability of each evaluation indicator increases, and the minus coefficient indicates that each achievement rate decreases.

Table. 12. Variables for evaluating incentive system

\begin{tabular}{|c|c|c|}
\hline & Job-Retainer & Job-Changer \\
\hline $\begin{array}{l}\text { Evaluation index of individual } \\
\text { workers }\end{array}$ & $\begin{array}{l}-\quad \text { earn more than average } \\
\text { - occupy the position of manager }\end{array}$ & $\begin{array}{l}\text { - } \quad \text { earn more than average } \\
\text { - } \quad \text { occupy the position of manager } \\
\text { increases of income (except JP) }\end{array}$ \\
\hline The priority when choosing job & $\begin{array}{l}\text { - } \quad \text { Company's status } \\
\text { - } \quad \text { Good personal relation } \\
\text { - } \quad \text { Good rewards (High salary etc.) } \\
\text { - } \text { Place that you want to work } \\
\text { - Appropriate work hours \& } \\
\text { - holidays } \\
\text { - } \text { Fair evaluationof employee } \\
\text { - } \quad \text { Emploar career path } \\
\text { - Opportunity of education etc. }\end{array}$ & \\
\hline
\end{tabular}

\section{Social incentive systems for Job-Retainer in n each country}

I'll show the relations between evaluation and attitudes toward job for the Job-Retainers regarding to promotion in table 12 , regarding to salary level in table 13 . 
First, we have statistically confirmed the existence of social incentive system regarding to promotion in China, Indonesia and Brazil. The status seeking attitude is evaluated in Indonesia and Brazil. The need of fair evaluation is evaluated in Brazil. The serious concerning about clear career path is evaluated in China and Indonesia. On the other hand, putting priority on good personal relation is less evaluated in Brazil.

Second, we have statistically confirmed the existence of social incentive system regarding to income in Japan, South Korea, China, United States and Brazil. The status seeking attitude is evaluated in United States. The need of work and life balance is evaluated in China. Contrary, the need of work and life balance is less evaluated in Japan. The serious concerning about good personal relation is less evaluated in South Korea and Brazil. The need of education opportunity by company is less evaluated in Brazil.

Here, we certified some difficulties of Japanese enterprise to utilize foreign human resources. Those who put priority on good personal relation are given penalties in South Korea and Brazil. This could prevent "context-oriented human asset" from accumulating in South Korea and Brazil. The serious concerning about clear career path, which is very difficult of Japanese company to offer, is seen in China, Indonesia and Brazil. And career opportunities in Japanese firms, which are losing international competitiveness, is not attractive for the status seeking workers in China and United States.

Table. 12. Highly evaluated job attitude in regard with promotion for Job-Retainer

\begin{tabular}{|c|c|c|c|c|c|c|c|c|c|c|c|c|c|c|}
\hline \multirow[t]{2}{*}{ Influence to Promotion } & \multicolumn{2}{|c|}{ JP } & \multicolumn{2}{|c|}{$\mathrm{KR}$} & \multicolumn{2}{|c|}{$\mathrm{CH}$} & \multicolumn{2}{|c|}{$\mathrm{I}$} & \multicolumn{2}{|c|}{$\mathrm{DE}$} & \multicolumn{2}{|c|}{ US } & \multicolumn{2}{|c|}{$\mathrm{BR}$} \\
\hline & Estimate & $\operatorname{Pr}(P \mid z)$ & Estimate & $\operatorname{Pr}(>\mid z)$ & Estimate & $\operatorname{Pr}(>|z|)$ & Estimate & $\operatorname{Pr}(P \mid z)$ & Estimate & $\operatorname{Pr}(>\mid z)$ & Estimate & $\operatorname{Pr}(>|z|)$ & Estimate & $\operatorname{Pr}(P \mid z)$ \\
\hline Total Model & & 0.114 & & $\underline{0.026}$ & & $\underline{0.080}$ & & $\underline{0.015}$ & & 0.310 & & 0.255 & & $\underline{0.045}$ \\
\hline (Intercept) & -1.561 & 0.000 & 11.850 & 0.993 & -0.871 & 0.084 & -2.981 & 0.000 & -1.454 & 0.000 & -1.007 & 0.061 & -1.380 & 0.049 \\
\hline Company's status & & & -15.335 & 0.990 & & & 0.466 & $\underline{\underline{0.049}}$ & & & & & 0.429 & $\underline{\underline{0.036}}$ \\
\hline Good personal relation & & & & & & & -0.105 & 0.650 & & & & & -0.328 & $\underline{0.055}$ \\
\hline Work assignment of you & & & & & 0.167 & 0.164 & & & & & & & & \\
\hline Good rewards (High salary etc.) & & & 0.254 & 0.164 & & & & & & & & & & \\
\hline Place that you want to work & 0.275 & $\underline{0.092}$ & & & & & & & & & 0.175 & 0.252 & & \\
\hline Appropriate work hours \& holidays & -0.171 & $\overline{0.234}$ & 0.297 & 0.107 & & & & & 0.029 & 0.813 & & & -0.289 & 0.255 \\
\hline Fair evaluation of employee & & & & & & & & & & & -0.246 & 0.281 & 0.285 & $\underline{0.090}$ \\
\hline Clear career path & & & & & 0.223 & $\underline{0.061}$ & 0.473 & 0.009 & 0.280 & 0.117 & & & & \\
\hline Employment stability & & & & & -0.083 & 0.556 & & & & & -0.141 & 0.313 & 0.410 & 0.210 \\
\hline
\end{tabular}

Significant level: "Gray background" $0.1 \%$, "Double underlined" $1 \%$, "Single underlined" $5 \%$

Table. 13. Highly evaluated job attitude in regard with salary for Job-Retainer

\begin{tabular}{|c|c|c|c|c|c|c|c|c|c|c|c|c|c|c|}
\hline \multirow[t]{2}{*}{ Influence to Income Level } & \multicolumn{2}{|c|}{ JP } & \multicolumn{2}{|c|}{$\mathrm{KR}$} & \multicolumn{2}{|c|}{$\mathrm{CH}$} & \multicolumn{2}{|c|}{ D } & \multicolumn{2}{|c|}{$\mathrm{DE}$} & \multicolumn{2}{|c|}{ US } & \multicolumn{2}{|c|}{$\mathrm{BR}$} \\
\hline & Estimate & $\operatorname{Pr}(>z)$ & Estimate & $\operatorname{Pr}(>\mid z)$ & Estimate & $\operatorname{Pr}(|z|)$ & Estimate & $\operatorname{Pr}(>\mid z)$ & Estimate & $\operatorname{Pr}(\gg \mid z)$ & Estimate & $\operatorname{Pr}(>\mid z)$ & Estimate & $\operatorname{Pr}(>\mid z)$ \\
\hline Total Model & & 0.016 & & $\underline{0.014}$ & & 0.018 & & 0.287 & & 0.151 & & 0.011 & & 0.047 \\
\hline (Intercept) & -0.047 & 0.914 & 0.617 & 0.162 & -1.298 & 0.152 & -0.186 & 0.799 & -0.270 & 0.375 & $-1.173\}$ & 0.016 & 0.131 & $\overline{0.877}$ \\
\hline Good personal relation & & & -0.252 & $\underline{\underline{0.040}}$ & & & & & & & $-0.281 \xi$ & 0.136 & -0.356 & $\underline{\underline{0.047}}$ \\
\hline Work assignment of you & & & & & 0.164 & 0.235 & & & & & & & -0.045 & 0.754 \\
\hline Good rewards (High salary etc.) & & & & & -0.188 & 0.193 & 0.006 & 0.968 & & & & & & \\
\hline Place that you want to work & 0.196 & 0.191 & & & -0.313 & 0.193 & & & -0.161 & 0.202 & & & & \\
\hline Appropriate work hours \& holidays & -0.265 & $\underline{0.014}$ & -0.310 & 0.009 & 0.401 & $\underline{0.019}$ & -0.289 & 0.241 & & & & & & \\
\hline Clear career path & & & & & & & & & & & 0.182 & 0.199 & -0.253 & 0.106 \\
\hline Employment stability & & & & & & & & & 0.101 & 0.257 & & & 0.090 & 0.510 \\
\hline Opportunity of eculcation etc. & & & & & 0.256 & 0.305 & -0.427 & 0.121 & & & $-0.095\}$ & 0.555 & -0.385 & $\underline{0.098}$ \\
\hline
\end{tabular}

Significant level: "Gray background" $0.1 \%$, "Double underlined" $1 \%$, "Single underlined" $5 \%$

\section{Social incentive system for Job-Changer in each country}

We illustrated the relations between evaluation and attitudes toward job for the Job-Changers regarding to promotion in table 14, regarding to salary level in table 15 , and regarding to the rise of salary when they changed job in Table 16.

First, we have statistically verified social incentive system regarding to promotion in Japan, China and Germany. Attitude for seeking status is affirmatively rewarded in Germany. The need for Clear career path is evaluated in China. Contrary, the putting priority on good personal relation leads negative estimation to job-changers in Japan.

Second, the existence of salary level incentive to certain attitudes is confirmed in Japan, China, Indonesia, United States and Brazil. The serious concerning about good personal relation is affirmatively rewarded only in Indonesia, 
but negatively rewarded in Japan and United States. The attitude of putting priority on work location lead good reward in China. The need for faire evaluation is evaluated in Japan.

Finally, we have statistically confirmed the social incentive system regarding to the increase of job-changers salary when changing work in South Korea, China, Indonesia, United States and Brazil. The attitude to seeking good reward is positively evaluated in South Korea and China. The need for clear career path is affirmatively valued in China, Indonesia, United States and Brazil. On the other hand, the attitude for seeking status in US and need for appropriate work hour and holydays in Indonesia are less rewarded.

We noticed the difficulty for Japanese company to attract job-changers in South Korea, China, Indonesia, United States and Brazil. We found that the attitudes to seek good reward or the need for clearer career path by changing job are well rewarded in those areas. Those incentive systems have inconsistency with that of Japanese companies' homeland office.

Table. 14. Highly evaluated job attitude in regard with salary for Job-Changer

\begin{tabular}{|c|c|c|c|c|c|c|c|c|c|c|c|c|c|c|}
\hline \multirow[t]{2}{*}{ Influence to Promotion } & \multicolumn{2}{|c|}{ JP } & \multicolumn{2}{|c|}{$\mathrm{KR}$} & \multicolumn{2}{|c|}{$\mathrm{CH}$} & \multicolumn{2}{|c|}{ ID } & \multicolumn{2}{|c|}{$\mathrm{DE}$} & \multicolumn{2}{|c|}{ US } & \multicolumn{2}{|c|}{$\mathrm{BR}$} \\
\hline & Estimate: & $\operatorname{Pr}(>z)$ & Estimate & $\operatorname{Pr}(\bullet z)$ & Estimate: & $\operatorname{Pr}(>|z|)$ & Estimate & $\operatorname{Pr}(\geqslant \mid z)$ & Estimate & $\operatorname{Pr}(>z)$ & Estimate & $\operatorname{Pr}(>z)$ & Estimate & $\operatorname{Pr}(>\mid z)$ \\
\hline Total Model & & $\underline{\underline{0.024}}$ & & 0.348 & & $\underline{0.053}$ & & 0.105 & & $\underline{0.057}$ & & 0.269 & & 0.379 \\
\hline (Intercept) & -1.358 & 0.011 & -0.670 & 0.340 & -0.269 & 0.571 & 0.011 & 0.975 & $-1.257\}$ & 0.036 & -0.723 & 0.054 & -1.055 & 0.009 \\
\hline Company's status & & & -0.682 & 0.190 & & & & & 0.456 & $\underline{0.091}$ & 0.214 & 0.271 & & \\
\hline Good personal relation & -0.258 & $\underline{0.057}$ & 0.014 & 0.942 & -0.170 & 0.179 & & & & & -0.186 & 0.267 & & \\
\hline Work assignment of you & & & & & & & & & 0.120 & 0.363 & & & & \\
\hline Good rewards (High salary etc.) & 0.139 & 0.327 & & & & & & & & & & & & \\
\hline Place that you want to & & & & & 0.070 & 0.611 & & & & & & & & \\
\hline Appropriate work hours \& holidays & & & & & & & -0.225 & 0.155 & -0.285 & 0.125 & & & 0.218 & 0.275 \\
\hline Fair evaluation of employee & 0.230 & 0.112 & 0.144 & 0.503 & & & -0.326 & 0.110 & & & & & & \\
\hline Clear career path & & & & & 0.179 & $\underline{\underline{0.043}}$ & & & & & & & & 0452 \\
\hline $\begin{array}{l}\text { Employment stability } \\
\text { Opportunity of education etc. }\end{array}$ & & & & & 0.269 & 0.230 & & & & & & & -0.099 & 0.452 \\
\hline & & & & & & & & & & & & & & \\
\hline
\end{tabular}

Table. 15. Highly evaluated job attitude in regard with salary for Job-Changer

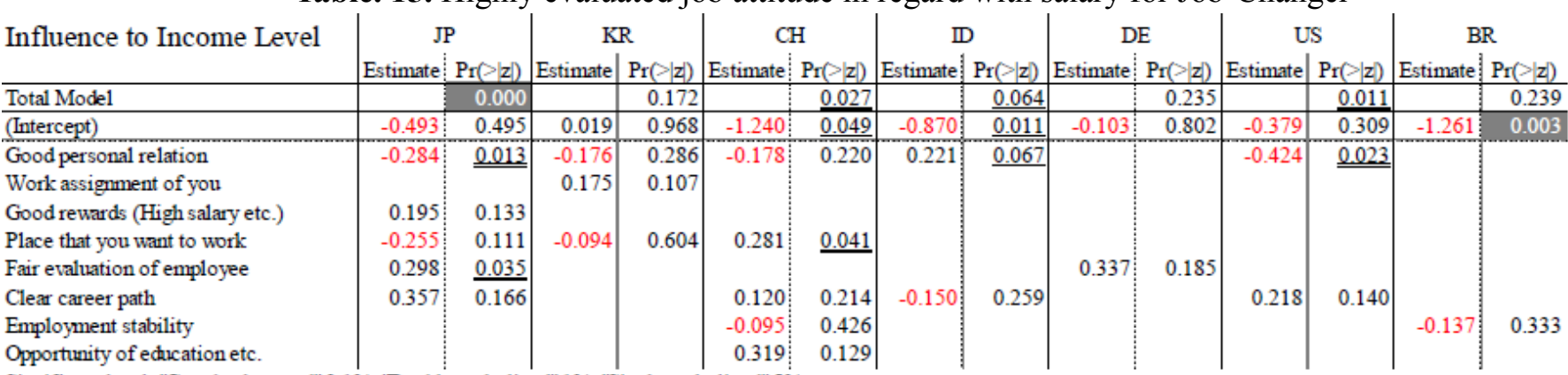

Opportunity of ecucation etc.

Significant level: "Gray background" $0.1 \%$, "Double underlined" 1\%, "Single underlined" $5 \%$

Table. 16. Highly evaluated job attitude in regard with salary increase when changed job

\begin{tabular}{|c|c|c|c|c|c|c|c|c|c|c|c|c|c|}
\hline \multirow[t]{2}{*}{ Influence to Income Change } & \multirow[t]{2}{*}{ JP } & \multicolumn{2}{|c|}{$\mathrm{KR}$} & \multicolumn{2}{|c|}{$\mathrm{CH}$} & \multicolumn{2}{|c|}{ ID } & \multicolumn{2}{|c|}{$\mathrm{DE}$} & \multicolumn{2}{|c|}{ US } & \multicolumn{2}{|c|}{$\mathrm{BR}$} \\
\hline & & Estimate & $\operatorname{Pr}(>\mathbf{z})$ & Estimate & $\operatorname{Pr}(>\mid z)$ & Estimate & $\operatorname{Pr}(>\mid z)$ & Estimate & $\operatorname{Pr}(>|z|)$ & Estimate & $\operatorname{Pr}(>\mid z)$ & Estimate & $\operatorname{Pr}(>\mid z)$ \\
\hline Total Model & & & $\underline{0.055}$ & & 0.000 & & $\underline{0.063}$ & & 0.117 & & 0.007 & & $\underline{0.079}$ \\
\hline (Intercept) & & -1.353 & 0.133 & 0.633 & 0.433 & 1.064 & 0.050 & 0.919 & 0.186 & 0.746 & 0.287 & 0.172 & 0.635 \\
\hline Company's status & & & & -0.157 & 0.395 & & & & & -0.359 & $\underline{0.078}$ & & \\
\hline Good personal relation & & -0.211 & 0.229 & & & & & -0.153 & 0.231 & -0.212 & 0.177 & & \\
\hline Work assignment of you & & 0.098 & 0.384 & & & & & & & & & & \\
\hline Good rewards (High salary etc.) & & 0.254 & $\underline{\underline{0.045}}$ & 0.394 & 0.003 & 0.043 & 0.720 & 0.210 & 0.164 & 0.167 & 0.174 & & \\
\hline Place that you want to work & & & & & & & & & & & & -0.161 & 0.331 \\
\hline Appropriate work hours \& holidays & & & & & & -0.263 & $\underline{0.089}$ & & & & & & \\
\hline Fair evaluation of employee & & & & -0.276 & 0.189 & & & & & -0.289 & 0.219 & & \\
\hline Clear career path & & 0.096 & 0.652 & 0.375 & 0.007 & 0.267 & $\underline{0.095}$ & -0.580 & 0.180 & 0.408 & $\underline{0.031}$ & 0.260 & $\underline{0.059}$ \\
\hline Employment stability & & & & -0.140 & 0.298 & & & & & & & & \\
\hline Opportunity of ecucation etc. & & 0.702 & 0.148 & & & & & & & & & & \\
\hline
\end{tabular}

Significant level: "Gray background" $0.1 \%$, "Double underlined" 1\%, "Single underlined" $5 \%$ 


\section{Conclusions}

We have investigated the reason why Japanese companies luck the ability to utilize external human resources. As I mentioned as hypotheses, the co-evolution between socially accumulated human asset and dominant organizational architecture in each economic cluster could be the cause of this.

Firstly, we confirmed the Japanese market of experienced labor is imperfect on chapter 3. Regarding to the contract term and work time length, job-changers' positions are usually weaker than job-retainers' one in Japan. Also, the average salary level of job-changers is lower than that of job-retainers. These facts might testify 1st hypothesis.

Secondly, we verified that different type of human asset is accumulated in each economic cluster based on difference between labor market structure on the former half of chapter 4 . The top priority element of job is good personal relation only in Japan. In contrast, the top priority element of job is good rewards. Because the performance depends on team work level for "context-oriented human asset" [12] [19] [20], the top priority on good personal relation might indicate social accumulation of "context-oriented human asset" in Japan. Because the job description of "individual human asset" might be highly defined and the performance of them could be easily evaluated independently, the top priority on good rewards would indicate social accumulation of "individual human asset". Thus, we could conclude that 2 nd hypothesis is verified. Though, we have to emphasize the findings are not so simple. More workers of Japan, Germany and Brazil put priority on good personal relation than the other workers of countries. We need further investigation to find the causes of simultaneous emphasis on both good rewards and good personal relation.

Finally, we certified the existence of social incentive system to enhance the certain type human asset accumulation on later part of chapter 4. Regarding to job-retainers, the need for clear career path is positively rewards in China, Indonesia and Brazil, but the priority on good personal relation is negatively evaluated in South Korea and Brazil. Regarding to job-changer, we found that the attitudes to seek good reward or the need for clearer career path are well rewarded in South Korea, China, Indonesia, United States and Brazil. These findings indicate the existence of incentive system to accumulate "individual human asset" in foreign countries except Germany, especially for job-changers. Thus, we could judge the 3rd hypothesis is certified partly. We couldn't find clear incentive system to enhance the accumulation of Germany half individual and half context-oriented human asset. This might be caused by the existence of special regulation of labor market a and organizational governance system in Germany [21].

Here, we could lead this conclusion. We confirmed the accumulation of "individual human asset" and the affirmative evaluation for attitude seeking job opportunities are seen in South Korea, China, Indonesia, United States and Brazil. Those two combined to prevent almost of all Japanese companies from providing attractive job opportunities for workers of the 5 countries, because the combination is inconsistent with Japanese homeland combination of "context-oriented human asset" and seniority based rewards.

\subsection{Implications and Limitations}

All Japanese company couldn't offer attractive job opportunities to foreign workers by integrating human resource management globally, or not? Serval possibilities are mentioned in the literatures [17] [20]. According the literature, I could list three possibilities. First, I could mention the fact that H-System company cluster has emerged in both industries of ICT and retail, because liquidity of labor force of younger generation is getting higher in Japan. Second, Japanese company could evolve to RE mode, which is operated in project base cross-function team. They could offer attractive well defined job opportunity. But to execute this change they should decentralize the HR management but centralize the HR management regulation. Third, one country could have serval organizational architecture by dividing the economy system into two or more clusters like United States. We can see H-mode and SV-mode simultaneously in United States now. These possibilities could not be realized by single company, government policy change would be needed too. 
The further modeling and investigation should be necessary to establish more practical policy development as I mentioned. Discussing this research question in two type human asset is too simplified. We should characterize G-mode human asset at least.

\section{References}

[1] D. Drabe, S. Hauff, and N. F. Richter, "Job satisfaction in aging workforces: an analysis of the USA, Japan and Germany,” Int. J. Hum. Resour. Manag., vol. 26, no. 6, pp. 783-805, 2015, doi: 10.1080/09585192.2014.939101.

[2] T. Sekiguchi, "Theoretical implications from the case of performance-based human resource management practices in Japan: Management fashion, institutionalization and strategic human resource management perspectives," Int. J. Hum. Resour. Manag., vol. 24, no. 3, pp. 471-486, 2013, doi: 10.1080/09585192.2012.703414.

[3] S. Wood, “Human resource management and performance,” Int. J. Manag. Rev., vol. 1, no. 4, pp. 367-413, 1999, doi: 10.1111/1468-2370.00020.

[4] K. Aoki, R. Delbridge, and T. Endo, “Japanese human resource management' in post-bubble Japan,” Int. J. Hum. Resour. Manag., vol. 25, no. 18, pp. 2551-2572, 2014, doi: 10.1080/09585192.2012.722118.

[5] C. Moriguchi, "Japanese-style human resource management and its historical origins," Japan labor Rev., vol. 11, no. 3, pp. 58-77, 2014.

[6] Y. Kuwahara, "New Developments in Human Resource Management in Japan,” Asia Pacific J. Hum. Resour., vol. 31, no. 2, pp. 3-11, 1993, doi: 10.1177/103841119303100202.

[7] I. S. Meeting, "International Scientific Meeting,” no. June, 2007.

[8] P. DEBROUX, “Human Resource Management in Japan,” Manag. Hum. Resour. Asia-Pacific, pp. 64-81, 2020, doi: 10.4324/9780203157053-4.

[9] H. Conrad and H. Meyer-Ohle, "Overcoming the ethnocentric firm?-foreign fresh university graduate employment in Japan as a new international human resource development method,” Int. J. Hum. Resour. Manag., vol. 30, no. 17, pp. 2525-2543, 2019, doi: 10.1080/09585192.2017.1330275.

[10]H. J. Bernardin, “( PDF ) Human Resource Management.”

[11] G. Munchus, "Employer-employee based quality circles in Japan: human resource policy implications for American firms.," Acad. Manage. Rev., vol. 8, no. 2, pp. 255-261, 1983, doi: 10.5465/amr.1983.4284735.

[12]D. McDonald, "Strategic Human Resource Management Approaches to Workforce Diversity in Japan-Harnessing Corporate Culture for Organizational Competitiveness1," Glob. Bus. Rev., vol. 4, no. 1, pp. 99-114, 2003, doi: 10.1177/097215090300400107.

[13] J. Druker, "Strategy and Human Resource Management," Manag. Decis., vol. 41, no. 5, pp. 523-524, 2003, doi: 10.1108/00251740310479368.

[14] Y. Zhu, "Responding to the challenges of globalization: Human resource development in Japan," J. World Bus., vol. 39, no. 4, pp. 337-348, 2004, doi: 10.1016/j.jwb.2004.08.002.

[15] T. Suda, "Comparison of Human Resource Management between the Pharmaceutical and Electrical Industries in Japan,” World J. Manag., vol. 8, no. 1, pp. 170-188, 2017, doi: 10.21102/wjm.2017.03.81.13.

[16] J. Selmer, "Human resource management in Japan: Adjustment or transformation?,” Int. J. Manpow., vol. 22, no. 3, pp. 235-243, 2001, doi: 10.1108/01437720110398284.

[17]C. Ichniowski and K. Shaw, "The Effects of Human on Resource Economic Plants Management Systems Performance : An of and Japanese International Comparison,” Manage. Sci., vol. 45, no. 5, pp. 704-721, 1999.

[18]R. L. Clark and N. Ogawa, "Human resource policies and older workers in Japan," Gerontologist, vol. 36, no. 5, pp. 627-636, 1996, doi: 10.1093/geront/36.5.627. 
[19]S. Kim, "ROUTLEDGE HANDBOOK OF HUMAN RESOURCE Fang Lee Cooke Chapter 15 HUMAN RESOURCE MANAGEMENT IN HuMAn ResouRce MAnAgeMent in JApAn And soutH KoReA,” 2018.

[20] J. Benson, "Employment and Human Resource Management Developments in Japan," J. Comp. Asian Dev., vol. 4, no. 1, pp. 55-76, 2005, doi: 10.1080/15339114.2005.9678410.

[21]M. Dianingrum, N. Hermanto, and M. I. Rifa'i, "Expert System for Simulation of Pest and Disease Diagnosis in Onion Plant Using Putty Shafer Method and Rule-Based Approach,” IJIIS Int. J. Informatics Inf. Syst., vol. 2, no. 1, pp. 1-8, 2019, doi: 10.47738/ijiis.v2i1.8.

[22] T. Hariguna and M. Tsamara, "E-Government Asset Management Using the Extreme Programming," IJIIS Int. J. Informatics Inf. Syst., vol. 2, no. 1, pp. 24-32, 2019, doi: 10.47738/ijiis.v2i1.1.

[23] Y. N. Chi, "Modeling and Forecasting Long-Term Records of Mean Sea Level at Grand Isle, Louisiana: SARIMA, NARNN, and Mixed SARIMA-NARNN Models,” J. Appl. Data Sci., vol. 2, no. 2, pp. 1-13, 2021, doi: 10.47738 /jads.v2i2.27. 